\title{
Engineering of Viruses and Pathogens for Gain-of-Function Research
}

\author{
Sohail Rao, MD, MA, DPhil ${ }^{1,2}$ and Manish Singh, MD, FACS ${ }^{3}$ \\ ${ }^{1}$ Executive Vice President, DHR Health, 5501 S. McColl Road, Edinburg, Texas 78539 and President \\ \& Chief Executive Officer, DHR Health Institute for Research \& Development, 5323 S. McColl Road, \\ Edinburg, Texas 78539. \\ ORCID: https://orcid.org/0000-0001-5027-9992 \\ ${ }^{2}$ Correspondence should be addressed to: Sohail Rao, MD, MA, DPhil., DHR Health Institute for \\ Research \& Development, 5323 S. McColl Road, Edinburg, Texas 78539. Tel: (956) 362-2387. E-mail: \\ s.rao@dhr-rgv.com \\ ${ }^{3}$ Chief Executive Officer, DHR Health, 5501 S. McColl Road, Edinburg Tx 78539 \\ ORCID: Manish Singh: https://orcid.org/0000-0003-4146-3282
}

Received 05/18/2021

Accepted for publication 06/08/2021

Published 06/08/2021

Keywords: Ethics, Laboratory, Pathogens, Influenza, NIAID, Gain of Function

Ethical concerns related to engineering of viruses and pathogens for gain-of-function (GoF) research has been widely debated in the literature (1). Scientists are conflicted as to the value of GoF research which has been used in the past to enhance viral pathogenicity, transmissibility, antigenicity, and tropism (2-4). The primary objective of these experiments was to gain a better understanding of the pathogen, allowing investigators to develop a more reliable predictive models for emerging infectious diseases and to combat them with effective vaccines and other therapeutic agents. This issue was recently highlighted during a U.S. congressional hearing aimed at elucidating the origin of the SARS-CoV-2 pandemic that has infected over 173 million worldwide and has resulted in the death of over 3.7 million people $(5,6)$. In US alone, SARS-CoV-2 has infected over 33 million and caused the death of over 594,000 people (7).

Perhaps the most controversial research related to GoF was the modification of H5NI avian flu virus (8). In these experiments, the investigators used reverse genetics that enhanced the lethality of the virus, confirming that $\mathrm{H} 5 \mathrm{~N} 1$ can jump from birds to mammals and could be efficiently transmitted between humans. These studies that were funded by the National Institute of Allergy and Infectious Disease (NIAID) raised numerous ethical and public health concerns (9). It was argued that the risk posed by the inadvertent escape of laboratory engineered $\mathrm{H} 5 \mathrm{~N} 1$ into the community far outweighs the benefit that would be gained from these highly perilous experiments. The controversy escalated when the
National Science Advisory Board for Biosecurity (NSABB) issued its recommendation that the controversial $\mathrm{H} 5 \mathrm{~N} 1$ reports be published with significant redactions (10). NSABB recommended that methodology and other details that could enable replication of the experiments by those who seek to do harm are to be redacted. This controversial research and the NSABB recommendation divided the scientific community, which recognized that the easily transmitted laboratory engineered GoF H5N1 could be extraordinarily lethal.

In 2014, a series of mishaps in which highly pathogenic microbes were mishandled by various laboratories in the U.S. Centers for Disease Control and Prevention (CDC) resulted in closure of two labs and halted some biological shipments (11). The cases included an accidental shipment of live anthrax; the discovery of forgotten, live smallpox samples; and a newly revealed incident in which a dangerous influenza strain was accidentally shipped from CDC to another laboratory. These and other similar mishaps involving GoF experiments resulted, in the issuance of a moratorium by the U.S. Government pausing deliberative process and research funding for selected GoF research involving Influenza, MERS, and SARS viruses in 2014 (12).

Subsequent to implementation of this "pause," both the National Research Council and the Institute of Medicine organized a number of symposiums to discuss the potential risks and benefits of GoF research. These deliberations ultimately resulted in the publication by NSABB 
"Recommendations for the Evaluation and Oversight of Proposed Gain-of-Function Research" (13). This was followed by the publication by the US Department of Health \& Human Services "Recommended Policy Guidance for Departmental Development of Review Mechanisms for Potential Pandemic Pathogen Care and Oversight" (P3CO) (14). With these $\mathrm{P} 3 \mathrm{CO}$ recommendations in place, in 2017, the $\mathrm{NIH}$ lifted the moratorium into GoF research because it was deemed to be important in helping identify, understand, and develop strategies and effective countermeasures against rapidly evolving pathogens that pose a threat to public health (15).

With the lifting of this moratorium, NIAID through an intermediate organization, funded GoF research to be conducted on bat coronavirus in collaboration with the Institute of Virology, Wuhan, China (16). The primary objective of this funding was to conduct GoF research for the purpose of understanding how bat coronaviruses could mutate to attack humans. It is unclear what and/or how this GoF research on bat coronavirus may have contributed to the current COVID-19 pandemic that has devastated the social and economic fabric globally.

Despite the importance of GoF research and the fact that this recent funding has now been suspended by the NIAID, one must recognize that accidental escape of engineered pathogens and viruses do pose a catastrophic existential risk for the global human community and every effort must be exercised to prevent (not minimize) this risk.

\section{Diclosures}

SR declares no conflicts of interest.

MS declares no conflicts of interest.

\section{References}

1. Selgelid, M.J. Gain-of-Function Research: Ethical Analysis. Sci. Eng. Ethics (2016) 22:923-964.

2. Kuo, L., Godeke, G. J., Raamsman, M. J., Masters, P. S., and Rottier, P. J. (2000). "Retargeting of coronavirus by substitution of the spike glycoprotein ectodomain: Crossing the host cell species barrier". Journal of Virology. 74 (3): 1393-406.

3. Imai, M., Watanabe, T., Hatta, M., et al. (2012). "Experimental adaptation of an influenza H5 HA confers respiratory droplet transmission to a reassortant $\mathrm{H} 5$ HA/H1N1 virus in ferrets". Nature. 486(7403): 420-428.

4. Zhang, Y., Zhang, Q., Kong, H., et al. (2013). "H5N1 Hybrid Viruses Bearing 2009/H1N1 Virus Genes Transmit in Guinea Pigs by Respiratory Droplet". Science. 340 (6139): 1459-1463.
5. World Health Organization Coronavirus (COVID-19) Dashboard. Accessed June 08, 2021; 11:53 a.m. Central European Summer Time. https://covid19.who.int/

6. Watkins, M. Rand Paul and Anthony Fauci Argue Over Theories About COVID-19's Origin. USA Today. 2021 May 11. https://news.yahoo.com/rand-paul-anthonyfauci-argue-190133625.html

7. U.S Center for Disease Control and Prevention COVID19 Dashboard. Accessed June 08, 2021; 09:22 a.m. Central Standard Time. https://covid.cdc.gov/covid-datatracker/\#datatracker-home

8. Martin Enserink. Controversial Studies Give a Deadly Flu Virus Wings. Science 02 Dec 2011:Vol. 334, Issue 6060, pp. 1192-1193

9. Pavia, A.T. Laboratory Creation of a Highly Transmissible H5N1 Influenza Virus: Balancing Substantial Risks and Real Benefits. Ann Int Med. 2012 March 20; 156(2): 463-465.

10. News Media Branch. Press Statement on the NSABB Review of H5N1 Research. NIH Office of the Director. 2011 Dec 20. https://www.nih.gov/news-events/newsreleases/press-statement-nsabb-review-h5n1-research

11. Kaiser, J. Lab Incidents Lead to Safety Crackdown at CDC. Science: News. 2014 July 13. https://www.sciencemag.org/news/2014/07/labincidents-lead-safety-crackdown-cdc

12. U.S. Government Gain-of-Function Deliberative Process and Research Funding Pause on Selected Gain-ofFunction Research Involving Influenza, MERS, and SARS Viruses. https://www.phe.gov/s3/dualuse/Documents/gain-offunction.pdf

13. Recommendations for the Evaluation and Oversight of Proposed Gain-of-Function Research. 2016. https://web.archive.org/web/20170107112313/https://os p.od.nih.gov/sites/default/files/resources/NSABB Final Report Recommendations Evaluation Oversight Propo sed Gain of Function Research.pdf

14. Recommended Policy Guidance for Departmental Development of Review Mechanisms for Potential Pandemic Pathogen Care and Oversight. 2017 Jan 9. https://www.phe.gov/s3/dualuse/Documents/P3COFinalGuidanceStatement.pdf

15. Collins, F.S. NIH Lifts Funding Pause on Gain-ofFunction Research. 2017. The NIH Director. 2017 Dec 19. https://www.nih.gov/about-nih/who-we-are/nihdirector/statements/nih-lifts-funding-pause-gainfunction-research.

16. Branswell, H. NIH awards $\$ 7.5$ million grant to EcoHealth Alliance, months after uproar over political interference. STAT: In the Lab. 2020 Aug 27. https://www.statnews.com/2020/08/27/nih-awardsgrant-to-ecohealth-alliance-months-after-uproar-overpolitical-interference/ 